Original research article

\title{
Thoracolumbar burst fractures requiring instrumented fusion: Should reducted bone fragments be removed? A retrospective study
}

\author{
Can Yaldiz ${ }^{a, *}$, Klyasettin Asil ${ }^{b}$, Birol Özkal $^{c}$, Dauut Ceylan ${ }^{a}$, Tibet Kacira ${ }^{a}$ \\ a Sakarya University Training and Research Hospital, Department of Neurosurgery, Sakarya, Turkey \\ ${ }^{\mathrm{b}}$ Sakarya University Training and Research Hospital, Department of Radiology, Sakarya, Turkey \\ c Alanya Government Hospital, Clinic of Neurosurgery, Alanya, Turkey
}

\section{A R T I C L E I N F O}

Article history:

Received 19 February 2015

Accepted 26 August 2015

Available online 4 September 2015

Keywords:

Bone fragment

Posterior spinal instrumentation

Thoracolumbar burst fracture

\begin{abstract}
A B S T R A C T
Background: Thoracolumbar burst fractures are common clinical entity encountered in neurosurgical practice, accounting for $10-20 \%$ of all spinal fractures. Clinical picture could be devastating due to severe neurological deficits which lead the patients dependent both socially and emotionally.

Materials and methods: This study compared two groups of patients who were operated because of thoracolumbar burst fracture secondary to spinal trauma in terms of neurologic deficits, degree of improvement, and radiologic measurements at one-year follow-up. The first group (group I) included the patients who underwent posterior total laminectomy, peroperative reduction of intracanal bone fragments, and posterior spinal instrumentation and the second group (group II) included the patients who underwent total laminectomy, and spinal instrumentation without reduction of free bone fragments.

Results: Neither group showed significant correlation with any measurement parameter. Radiological assessments and clinical improvements did not disclosed significant difference between the two groups at one-year follow-up.

Conclusion: Retropulsion of free bone fragments extend the time of surgery and causes complications. This study found that there is no need to retropulse the bone fragments in the spinal canal in patients with unstable burst fractures who underwent total laminectomy and posterior long segment stabilization.
\end{abstract}

(C) 2015 Polish Neurological Society. Published by Elsevier Sp. z o.o. All rights reserved.

\section{Introduction}

The thoracolumbar region is one of the most important biomechanic transition zone in which rigid thoracic kyphosis and flexible lumbar lordosis meet. So that in this zone forces act upon in different directions which makes this zone vulnerable to the spinal trauma [1-7]. Nearly $90 \%$ of all spinal fractures occur in thoracolumbar area, $10-20 \%$ of which is burst fractures. Neurological deficits, from simple

\footnotetext{
* Corresponding author at: Department of Neurosurgery, Sakarya Training and Research Hospital, Sakarya, Turkey. Tel.: +90 2642750090 1460; fax: +90 3643460101; mobile: +90 5053572222.

E-mail address: drcanyaldiz@yahoo.com (C. Yaldiz).

http://dx.doi.org/10.1016/j.pjnns.2015.08.005

0028-3843/@ 2015 Polish Neurological Society. Published by Elsevier Sp. z o.o. All rights reserved.
} 
paresthesia to severe plegia can be developed in most patients [2,13-15].

Advanced imaging techniques have led us to make rapid diagnose and treatment of these fractures. In case of emergency, bone window definition of CT, especially axial $\mathrm{CT}$, is very helpful for evaluation of the fractures and free fragments if present, in the spinal canal and MRI which is now gold standard to evaluate the spinal cord injury [1-4,15-27].

TLBFs are generally unstable fractures and [28] surgery is typically required to restore the spinal canal and vertebral alignment [3,28-30]. Surgery decompresses the spinal cord and corrects the vertebral column alignment by using laminectomy and applying transpedicular screws [30]. Surgical procedures have been further developed based on technological advancements. Dicks' internal fixators (providing posterior reduction, distraction, and stabilization), universal spinal systems, cancellous bone graft techniques defined by Daniaux, and transpedicular screw systems are examples of such surgical advancements [31].

Spontaneous resorption of bone fragments in the spinal canal with or without instrumentation has been reported in some cases $[3,30]$ and also surgical and conservative treatment strategies for patients without neurologic deficits have been discussed extensively in the literature [3,31-33].

This study compared the two groups of patients in whom either reduction of free bone fragments was performed or not in addition to laminectomy and posterior instrumentation following TLBFs with respect to clinical and radiological outcomes at one-year follow-up after surgery.

\section{Materials and methods}

This retrospective analysis consisted of 40 patients who were admitted to the emergency department between 2011 and 2013 and diagnosed with unstable TLBFs secondary to trauma to the spine. All the patients were treated with decompression and posterior instrumentation.

Patients were divided into two groups; each of which included 20 patients. The first group (group I) had total laminectomy and posterior stabilization and the group II had the same surgical treatment with the reduction of free bone fragments.

Pre- and postoperative Benzel-Larson Grading (Table 1) [34] and American Spinal Injury Association (ASIA) Classification were examined by using axial and multiplanar reconstructed

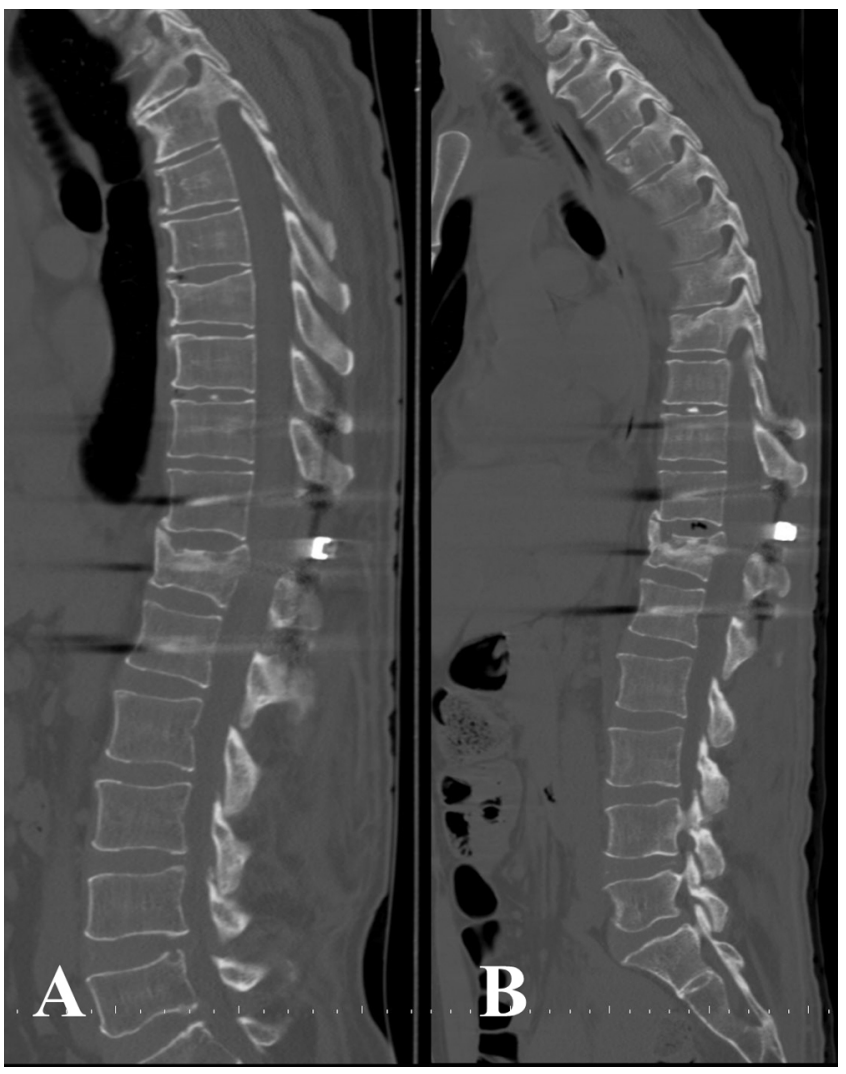

Image 1 - Sagittal MPR image in CT analysis of one patient from each group. (a) Sagittal MPR image in CT analysis of a patient with reduction of free fragments. (b) Sagittal MPR image in CT analysis of a patient without reduction of free fragments.

CT images (Image 1). The clinical improvement ratio was determined by substracting the preoperative Benzel-Larson Grading and American Spinal Injury Association (ASIA) Classification values from the postoperative values.

In $\mathrm{CT}$ analyses, the formula $2 \mathrm{~F} /(\mathrm{A}+\mathrm{B}) \times 100$ was used to calculate the degree of the vertebra compression; where $F$ is the height of the fractured vertebral body, $A$ is the height of the upper vertebral body, and $B$ is the height of the lower vertebral body (Image $2 a$ and $b$ ). The formula, $\alpha=(1-x / y) \times 100$ was used

\section{Table 1 - Benzel-Larson neurological grading system of thoracic and lumbar spine injuries with regard to myelopathic} function.

\begin{tabular}{|c|c|}
\hline Grade & Description \\
\hline I & Complete functional neural transection: no motor or sensory function \\
\hline II & Motor complete: no voluntary motor function with preservation of some sensation \\
\hline III & Motor incomplete - nonfunctional: minimal nonfunctional voluntary motor function \\
\hline IV & $\begin{array}{l}\text { Motor incomplete - functional (nonambulatory): some functional motor control that is useful but not sufficient for independent } \\
\text { walking }\end{array}$ \\
\hline $\mathrm{V}$ & $\begin{array}{l}\text { Motor incomplete - functional (limited ambulation): walking with assistance or unassisted but with significant difficulty that } \\
\text { limits patient mobility }\end{array}$ \\
\hline VI & $\begin{array}{l}\text { Motor incomplete - functional (unlimited ambulation): difficulty with micturition; significant motor radiculopathy; discoordinated } \\
\text { gait }\end{array}$ \\
\hline VII & Normal: neurologically intact or minimal deficits that cause no functional difficulties \\
\hline
\end{tabular}




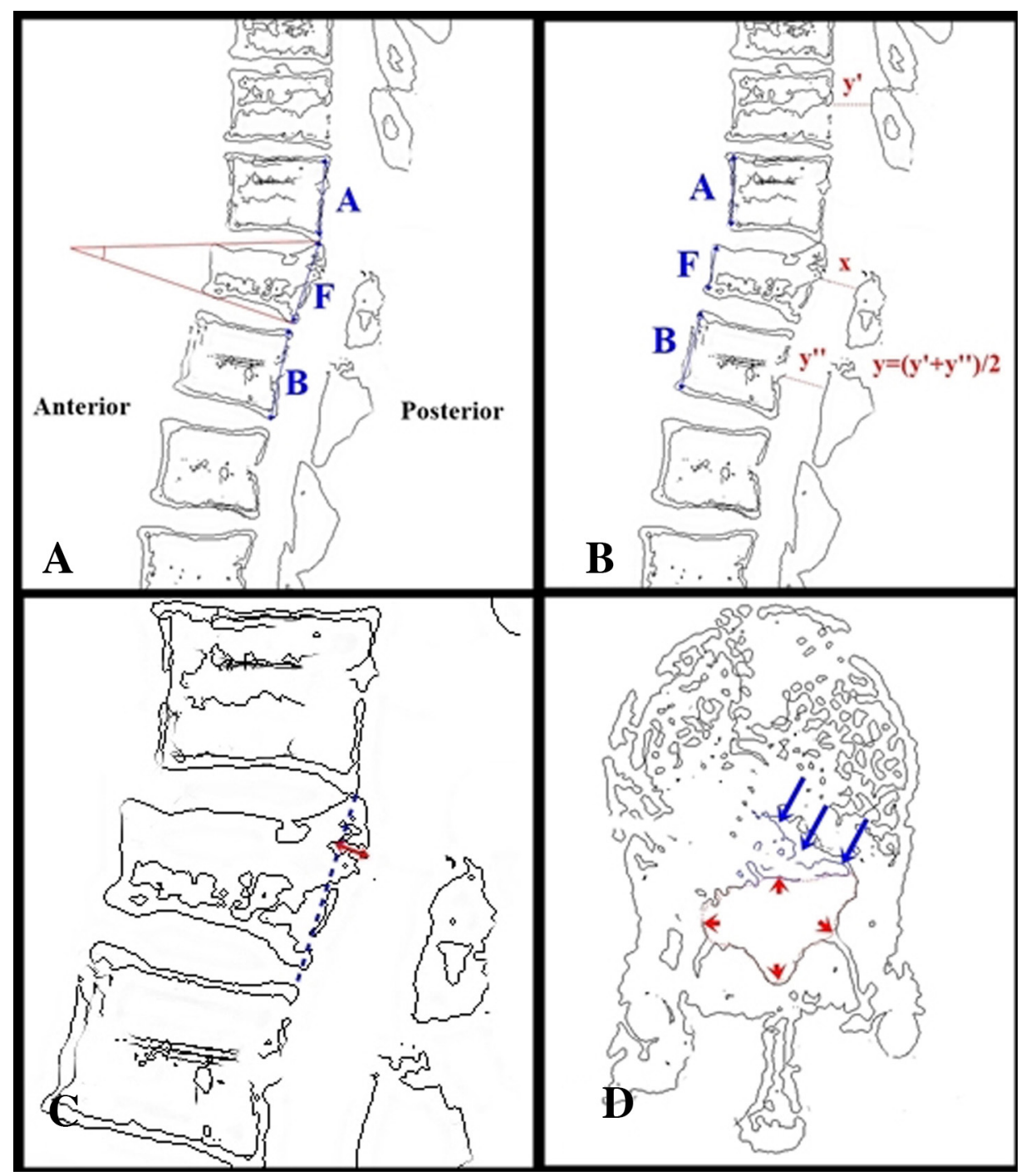

Image 2 - Schematic of radiologic measurements. (a) Kyphotic angle: the angle that connects the lines passing through superior and inferior endplates of vertebra (lost height due to trauma; red lines). Composition of posterior section of vertebra (blue lines): $2 F /(A+B) \times 100 F$ to give the height of the fractured vertebral body. Here, $A$ is the height of the upper vertebral body, and $B$ is the height of the lower vertebral body. (b) Composition of anterior section of vertebra (blue lines): $2 F /(A+B)$ $\times 100 \mathrm{~F}$. The height of the fractured vertebral body, where $A$ is the height of the upper vertebral body, and $B$ is the height of the lower vertebral body. Compromise ratio in the canal diameter (red lines): $\alpha=(1-x / y) \times 100$. Here $\alpha$ is the percentage of canal compromise, $x$ is the narrowest mid-sagittal diameter of the spinal canal at the level of injury, and $y$ is the average midsagittal diameter of the first upper level. The $\left(y^{\prime}\right)$ and lower level $\left(y^{\prime \prime}\right)$ are measured in multiplanar reconstruction images in CT. (c) The site with maximum posterior displacement in the vertebra fragment canal (blue dotted line) that connects the upper posterior corners of a lower vertebra corpus and a lower posterior of an upper vertebral body according to the vertebra with height loss (red line). (d) Canal area compromise ratio in axial CT analyses (red dotted line): $\alpha=(1-x / y) \times 100$. Here $\alpha$ is the percentage of canal compromise, $x$ is the narrowest mid-sagittal diameter of the spinal canal at the level of injury, and $y$ is the average mid-sagittal area of the first upper level $\left(y^{\prime}\right)$ and lower level $\left(y^{\prime \prime}\right)$ that can be measured in multiplanar reconstruction images in CT. Free fragments (blue arrows) can also be observed. (For interpretation of the references to color in this figure legend, the reader is referred to the web version of this article.)

separately to calculate canal compromise in sagittal Multiplanar reformatting (MPR) images and diameter in axial CT sections. Here, $\alpha$ is the percentage of canal compromise, and $x$ is the narrowest mid-sagittal diameter or area of the spinal canal at the level of injury. Term y is the average mid-sagittal diameter of the first upper level and the first lower level that can be measured in multiplanar CT (Image $2 \mathrm{a}$ and d). The fractured vertebral body angle of kyphotic deformity was measured as the angle between the margin of the upper level vertebral body and the margin of the lower vertebral body (Image 2a). Furthermore, the site of the highest posterior displacement was measured in the canal of the vertebra fragment by using the line connecting 
the lower posterior corners of an upper vertebral body and the upper posterior corners of a lower vertebral body (Image 2c). The spinal canal was measured, where the fracture had been occurred, between upper stable vertebral body and lower stable vertebral body that did not coincide the neural foramens. Patient age, sex, level of injury, type of injury, surgical instrumentation, and spinal canal intervention were all recorded during enrollment.

\subsection{Inclusion and exclusion criteria}

Cases were retrospectively evaluated. The following cases were excluded: patients under the age 18, patients with a canal diameter of $\leq 30 \%$, patients who were evaluated as stable fractures and conservatively followed-up, patients who underwent more than 3 level posterior spinal instrumentation and were not implanted with transpedicular screws at the fracture level, patients who underwent posterior segmental instrumentation, anterior corpectomy, and cage applications, patients who did not undergo decompressive laminectomy at the fracture level; patients who had fractures at three or more levels; and patients who were operated on after $24 \mathrm{~h}$ following the trauma. The clinical status of the patients were not been considered while the groups had been created. The indications for surgical treatment were based on the Denis criteria [35].

\subsection{Medical treatment}

Both groups were given a $30 \mathrm{mg} / \mathrm{kg}$ bolus of methylprednisolone within $15 \mathrm{~min}$. A $5.4 \mathrm{mg} / \mathrm{kg}$ dose was continued in the next $23 \mathrm{~h}$ [26]. Medical therapy was performed in both groups except for those included in Benzel-Larson grade 7 [5].

\subsection{Surgical technique}

The surgical technique has been well-defined and we here mention shortly. All patients were taken to the operating room for immediate surgery after the diagnostic work-up was completed in the emergency department. Paravertebral muscles were dissected bilaterally and at the fracture level total laminectomy together with minimal facetectomy were performed to all patients. However; partial laminectomies were performed at the upper and lower stable (no fractures observed) levels and the nerve roots were decompressed bilaterally. In the group II, free bone fragments in the spinal canal were removed or reduced. Transpedincular screws were attached to one upper and two lower levels of the fracture site. The system was fixed with rods in vertical direction and the bone fragments from the spinal canal which was followed by the application of autologous and allogenic bone for the supporting of the system.

\subsection{Demographic data}

A total of 40 patients; 24 males and 16 females met our inclusion criteria. Tables 2 and 3 present the demographic data.

\subsection{Radiological studies}

We included patients who underwent multidetector computed tomography (MDCT) analysis at $0.5 \mathrm{~mm}$ cross-section
Table 2 - Distribution of patient groups according to age.

\begin{tabular}{lccc} 
Age & Female & Male & Total \\
\hline Group 1 & $33.8(n=7)$ & $40.2(n=13)$ & $37.96(n=20)$ \\
Group 2 & $39.8(n=9)$ & $38.3(n=11)$ & $38.98(n=20)$ \\
\hline
\end{tabular}

Table 3 - Distribution of groups according to levels (multiple fractures in 7 patients).

\begin{tabular}{lcccc} 
Levels & L2 & L1 & T12 & T11 \\
\hline Group 1 $(n=20)$ & 1 & 10 & 11 & 3 \\
Group 2 $(n=20)$ & 3 & 13 & 6 & - \\
\hline
\end{tabular}

Table 4 - Average radiologic value of CT measurements at the end of one year.

\begin{tabular}{lcc} 
& Mean (\%) & N \\
\hline Height loss ratio in vertebra posterior (Group II) & 12.7392 & 20 \\
Height loss ratio in vertebra posterior (Group I) & 15.7469 & 20 \\
Height loss ratio in vertebra anterior (Group II) & 35.9085 & 20 \\
Height loss ratio in vertebra anterior (Group I) & 46.2377 & 20 \\
Ratio of spinal canal compromise at the & 50.6923 & 20 \\
$\quad$ narrowest site (Group II) & & \\
Ratio of spinal canal compromise at the & 48.6154 & 20 \\
$\quad$ narrowest site (Group I) & & \\
Kyphotic angle (Group II) & 16.7023 & 20 \\
Kyphotic angle (Group I) & 18.8323 & 20 \\
\hline
\end{tabular}

intervals in supine position at the end of the first postoperative year. Vertebra compression ratios, spinal canal compromise ratios, kyphotic angle, and degree of the posterior displacement were measured on axial cross-sections and sagittal multiplanar reconstruction images (Image 2) in both groups and parameters were compared at one-year follow-up after surgery (Table 4).

\subsection{Statistical analysis}

NCSS (Number Cruncher Statistical System) 2007\&PASS (Power Analysis and Sample Size) 2008 Statistical Software (Utah, USA) programme were used for statistical analysis. We used a t-test for paired data, and the " $p$ " value less than 0.05 was considered to be statistically significant.

\section{Results}

The mean age of patients in both groups was similar; 37.96 and 38.98 years in the group I and II, respectively and the majority were male (Table 2). Most fractures occurred at the level of $\mathrm{T}_{12}$ and $L_{1}$ and in 4 in the group I and in 3 in the group II had fractures at more than one level (Table 3).

Analysis comparison between the both group showed no significant correlation in terms of all parameters (Table 5). At the end of the first year, axial CT images and sagittal MPR images of the patients showed no significant difference between control CT measurements and improvement levels of both groups who underwent surgical treatment (Table 6, Graph 1). 
Table 5 - Statistical correlation between the measurements of both groups at the end of one year.

\begin{tabular}{lll} 
Group I-II & N & Sig. \\
\hline Clinical improvement & 20 & .224 \\
Height loss ratio in vertebra posterior & 20 & .282 \\
Height loss ratio in vertebra anterior & 20 & .127 \\
Kyphotic angle & 20 & .565 \\
$\quad \begin{array}{l}\text { Ratio of compromise in diameter of spinal } \\
\text { canal at the narrowest site }\end{array}$ & 20 & .196 \\
$\begin{array}{l}\text { Ratio of compromise in area of spinal } \\
\text { canal at the narrowest site }\end{array}$ & 20 & .561 \\
$\begin{array}{l}\text { Maximum spinal displacement to canal } \\
\text { in bone fragment }\end{array}$ & 20 & .861 \\
\hline
\end{tabular}

Using the Benzel-Larson scores for group 1, we found no change in 5 patients, 7 patients in stage 1 recovery, and 8 patients in stage 2 or above. In group 2, no change was seen in 6 patients, 7 patients in stage 1 , and 7 patients in stage 2 or above. There was no statistical difference in clinical recovery between the groups I and II $(p>0.05)$.
Using the ASIA scores for group 1, we found no change in 8 patients, 9 patients in stage 1 recovery, and 3 patients in stage 2 or above. In group 2, no change was seen in 8 patients, 10 patients in stage 1 , and 2 patients in stage 2 or above. There was no statistical difference in clinical recovery between the groups I and II $(p>0.05)$.

Using the ASIA scores for group 1, we found no change in 5 patients which were classified as ASIA A and 9 patients classified as ASIA B. 4 of them showed improvement in motor strength and sensorial examination that increased one stage in status. 2 patients showed full setup and the status increased from ASIA D2 to E. 12 of the 20 patients showed no improvement in gaita incontinence and 1 patient was followed-up with trans uretreal catheter (Table 7).

Using the ASIA scores for group 2, we found no change in 6 patients which were classified as ASIA A and 8 patients classified as ASIA B. 5 of them showed improvement in motor strength and sensorial examination that increased one stage in status. 2 patients showed full setup and the status increased from ASIA D2 to E. 12 of the 20 patients showed no

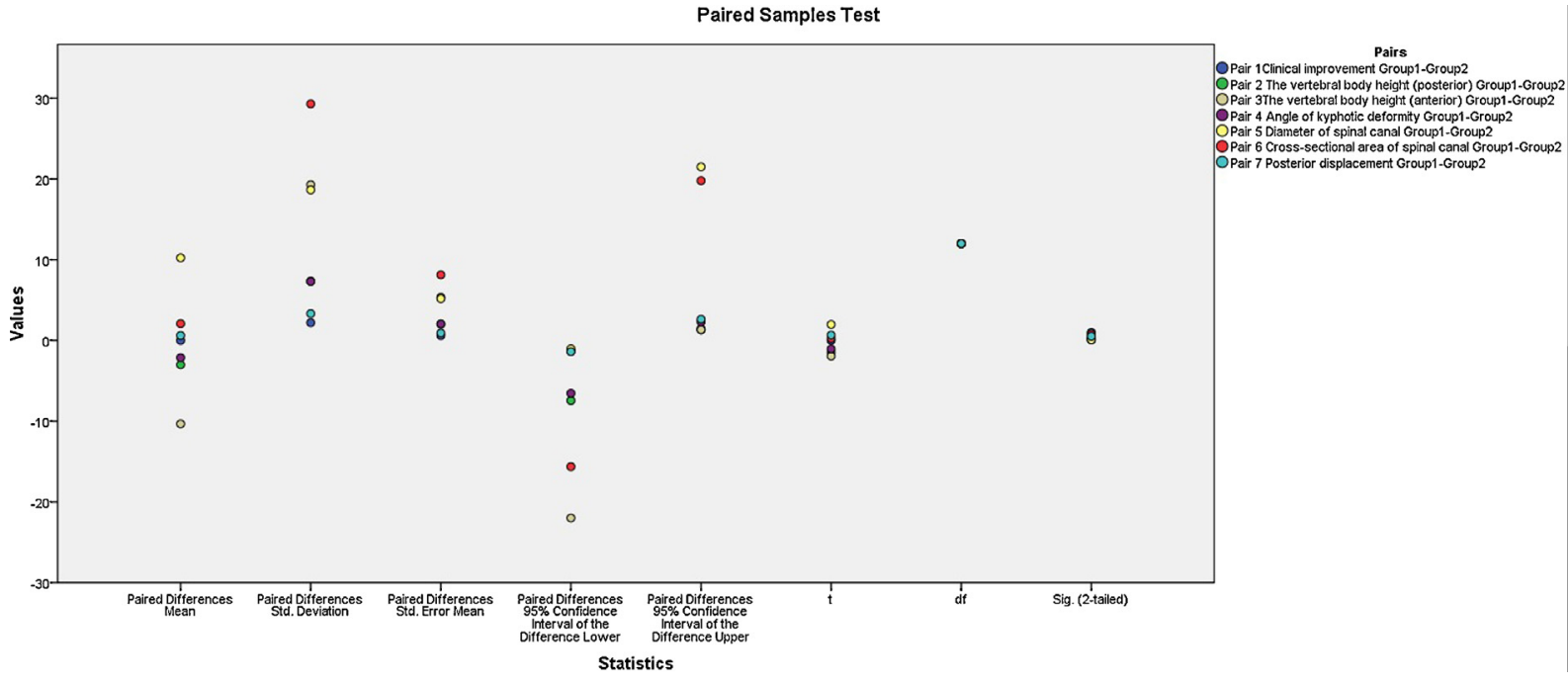

Graph 1 - Statistical difference between the measurements of both groups at the end of one year.

Table 6 - Statistical difference between the measurements of both groups at the end of one year.

Paired samples test

\begin{tabular}{|c|c|c|c|c|c|c|c|c|c|}
\hline & & \multicolumn{5}{|c|}{ Paired differences } & \multirow[t]{3}{*}{$t$} & \multirow[t]{3}{*}{ df } & \multirow{3}{*}{$\begin{array}{c}\text { Sig. } \\
\text { (2-tailed) }\end{array}$} \\
\hline & & \multirow[t]{2}{*}{ Mean } & \multirow[t]{2}{*}{$\begin{array}{c}\text { Std. } \\
\text { deviation }\end{array}$} & \multirow[t]{2}{*}{$\begin{array}{l}\text { Std. error } \\
\text { mean }\end{array}$} & \multicolumn{2}{|c|}{$\begin{array}{l}\text { 95\% Confidence } \\
\text { interval of the } \\
\text { difference }\end{array}$} & & & \\
\hline & & & & & Lower & Upper & & & \\
\hline Pair 1 & Clinical improvement (Group I-II) & .00000 & 2.19848 & .60975 & -1.32853 & 1.32853 & .000 & 20 & 1.000 \\
\hline Pair 2 & Posterior wall height loss (Group I-II) & -3.00769 & 7.34338 & 2.03669 & -7.44525 & 1.42987 & -1.477 & 20 & .165 \\
\hline Pair 3 & Anterior wall height loss (Group I-II) & -10.32923 & 19.29134 & 5.35045 & -21.98687 & 1.32841 & -1.931 & 20 & .078 \\
\hline Pair 4 & Kyphotic angle (Group I-II) & -2.13000 & 7.30809 & 2.02690 & -6.54623 & 2.28623 & -1.051 & 20 & .314 \\
\hline Pair 5 & Spinal canal diameter (Group I-II) & 10.23077 & 1865098 & 5.17285 & -1.03990 & 21.50144 & 1.978 & 20 & .071 \\
\hline Pair 6 & Spinal canal area (Group I-II) & 2.07692 & 29.29579 & 8.12519 & -15.62635 & 19.78019 & .256 & 20 & .800 \\
\hline Pair 7 & $\begin{array}{l}\text { Maximum displacement in canal } \\
\text { (Group I-II) }\end{array}$ & .61615 & 3.32123 & .92114 & -1.39084 & 2.62315 & .669 & 20 & .516 \\
\hline
\end{tabular}


Table 7 - Preoperative and postoperative BL and ASIA scores difference for the first 1 year in group 1.

\begin{tabular}{lcccc} 
Group 1 & $\begin{array}{c}\text { Benzel-Larson } \\
\text { preoperative grade }\end{array}$ & $\begin{array}{c}\text { Benzel-Larson postoperative } \\
\text { grade (1 year) }\end{array}$ & $\begin{array}{c}\text { ASIA preoperative } \\
\text { grade }\end{array}$ & $\begin{array}{c}\text { ASIA postoperative } \\
\text { grade (1 year) }\end{array}$ \\
\hline 1 & 1 & 1 & $\mathrm{~A}$ & $\mathrm{~A}$ \\
2 & 1 & 1 & $\mathrm{~A}$ & $\mathrm{~A}$ \\
3 & 1 & 1 & $\mathrm{~A}$ & $\mathrm{~A}$ \\
4 & 2 & 3 & $\mathrm{~B}$ & $\mathrm{~B}$ \\
5 & 2 & 3 & $\mathrm{~B}$ & $\mathrm{~B}$ \\
6 & 3 & 3 & $\mathrm{~B}$ & $\mathrm{C}$ \\
7 & 3 & 4 & $\mathrm{~B}$ & $\mathrm{C}$ \\
8 & 3 & 4 & $\mathrm{~B}$ & $\mathrm{C}$ \\
9 & 3 & $\mathrm{~A}$ & $\mathrm{~A}$ \\
10 & 1 & $\mathrm{~A}$ & $\mathrm{~A}$ \\
11 & 1 & $\mathrm{~B}$ & $\mathrm{D}$ \\
12 & 1 & $\mathrm{~B}$ & $\mathrm{C}$ \\
13 & 1 & 1 & $\mathrm{~B}$ & $\mathrm{D}$ \\
14 & 3 & 5 & $\mathrm{C}$ & $\mathrm{D}$ \\
15 & 3 & 4 & $\mathrm{C}$ & $\mathrm{D}$ \\
17 & 3 & 5 & $\mathrm{C}$ & $\mathrm{D}$ \\
18 & 3 & 5 & $\mathrm{D}$ & $\mathrm{D}$ \\
20 & 3 & 5 & $\mathrm{D}$ & $\mathrm{D}$ \\
\hline
\end{tabular}

Table 8 - Preoperative and postoperative BL and ASIA scores difference for the first 1 year in group 2.

\begin{tabular}{|c|c|c|c|c|}
\hline Group 2 & $\begin{array}{l}\text { Benzel-Larson preoperative } \\
\text { grade }\end{array}$ & $\begin{array}{l}\text { Benzel-Larson postoperative } \\
\text { grade ( } 1 \text { year) }\end{array}$ & $\begin{array}{l}\text { ASIA preoperative } \\
\text { grade }\end{array}$ & $\begin{array}{l}\text { ASIA postoperative } \\
\text { grade (1 year) }\end{array}$ \\
\hline 1 & 1 & 1 & A & A \\
\hline 2 & 1 & 1 & A & A \\
\hline 3 & 1 & 1 & A & A \\
\hline 4 & 1 & 1 & A & A \\
\hline 5 & 2 & 2 & A & A \\
\hline 6 & 1 & 1 & A & A \\
\hline 7 & 2 & 4 & B & C \\
\hline 8 & 2 & 3 & B & B \\
\hline 9 & 3 & 4 & B & C \\
\hline 10 & 3 & 4 & B & C \\
\hline 11 & 3 & 4 & B & C \\
\hline 12 & 3 & 4 & B & C \\
\hline 13 & 3 & 6 & B & D \\
\hline 14 & 3 & 5 & B & D \\
\hline 15 & 4 & 6 & C & D \\
\hline 16 & 4 & 6 & C & $\mathrm{D}$ \\
\hline 17 & 4 & 6 & C & $\mathrm{D}$ \\
\hline 18 & 5 & 6 & D & $\mathrm{D}$ \\
\hline 19 & 5 & 7 & D & E \\
\hline 20 & 5 & 7 & D & E \\
\hline
\end{tabular}

improvement in gaita incontinence and two patients were followed-up with trans uretreal catheter (Table 8).

We observed superficial wound infection in 2 cases. One had deep vein thrombosis, and one had sacral decubitus that was treated by wound dressing.

\section{Discussion}

The primary goal of surgery in TLBFs is to eliminate the compression of the neural structures, to restore anatomic alignment and to correct if possible, deformity in spinal vertebra [5]. Due to the technical advancements including the development of less invasive methods, optimal surgical approaches to these clinical conditions have been discussing during the last decade [6].

Neurologic deficits occur in $50-60 \%$ in TLBFs and can progress from simple paresthesia to hemiplegia [2,3]. A traumatized spine accompanied by a neurologic deficit is generally a complicated condition due to pathomechanical and biological factors. Since the mechanism(s) of spinal cord injury has not been understood clearly, it is very difficult to choose the best surgical approach which cannot guarantee the recovery of the neurologic deficits. While some centers 
claimed that anterior decompression is superior to other surgical approaches in terms of clinical improvements, but some others did not find any significant differences among the surgical approaches [6-11,36]. However, the common notion is that surgical decompression still continues to be the best treatment option today [6].

Yan et al. [12], reported that free bone fragments in the spinal canal is the main reason for the neurologic damage and removing the free bone fragments decompresses the neuronal tissue which make recovery faster. In their retrospective study, Deng et al. reported that posterior short segment stabilization, posterior laminectomy, and reduction of bone fragments in TLBFs were adequate to eliminate the tension on the neural tissues [2]. In a meta-analysis of 275 patients, Boerger et al. suggested that total laminectomy is not adequate to improve neurologic deficits and this claim is supported by a metaanalysis of 733 patients which found that the best results is possible the addition of the posterior stabilization to laminectomy $[6,13]$. Experimental and clinical studies underline that acute decompression is beneficial for partial neurologic deficits [14-17], and furthermore class I and class II clinical studies disclosed decompressive treatment has a significant role in neurologic improvement [36].

Timing of surgery is still continues to be an enigma. Cengiz et al. reported that neurologic improvement was not affected in patients who underwent surgery within a period of $72 \mathrm{~h}$ or longer [18], while $\mathrm{Li}$ et al. reported that decompression performed in the first $24 \mathrm{~h}$ was adequate and if performed in the first $8 \mathrm{~h}$, secondary neuronal injury can be reversed [7].

It is likely that timing of the surgery depends on the neurological situation, the severity of the trauma, accompanying systemic traumas and the number of the fractured vertebrae. Nevertheless, the early surgery seems to be optimal as soon as the clinical condition of the patient is stabilized [3740]. Roy-Camille et al. [39] reported that the surgical treatment must be done as quickly as possible. If the cord injury is incomplete and neurological conditions are not worsening, then the surgery can be done in $24-48 \mathrm{~h}$ to avoid bleeding. If a complete cord injury has occurred, then urgent surgical decompression must be done. Urgent decompression has been reported to increase neurological recovery. In our study, we observed neurologic improvement in all patients who underwent urgent spinal decompression in the first $24 \mathrm{~h}$ $(p>0.005)$. Thus, cases performed more than $24 \mathrm{~h}$ after injury were excluded from our study.

The choice of the surgical procedures in thoracolumbar vertebrae fractures remains unclear $[16,22,38,39]$. The type of the fracture, stability, the stenosis of the spinal canal and the neurological situation of the patient are important factors for choosing the best surgical procedure [5-11,38-41]. Unstable corpus fractures must be treated with both anterior and posterior approaches. Most reports state that there is no difference in recovery between the anterior and posterior procedures in incomplete spinal cord injury but sufficient spinal cord decompression can be done with anterior procedures. However, risk of major vein and visceral organ injuries is high and technical difficulties regarding to the anterior surgical interventions are drawbacks. On the other hand, the posterior procedures rarely provide sufficient cord decompression with fewer complications. So that the majority of spinal surgeons are performing posterior approach because of easy to perform in addition to the above advantages.

Some authors suggest that combined anterior and posterior approaches should be performed together in order to have sufficient decompression and for the stability of the spine $[4,5,19,21,22,42]$. Combined approach in severe TLBFs with $\geq 20 \%$ canal compromise and $\geq 50 \%$ height loss is one of the most widely recognized surgical approach. This approach most effectively decompressess the spinal canal, leads to surgeon to recover the stability $[5,19]$. Different notions have also been reported in the literature with respect to the type of surgical approaches. Oprel et al. reported that a single posterior approach is more effective compared to a combined approach in selected patients [4]. Danisa et al. compared posterior and combined approaches and found no significant difference [20]. Recent studies report that anterior, posterior, or combined approaches are not superior to one another $[5,19,21,22]$. Our patients had an average posterior vertebra height loss of $8.5-15.7 \%$ and canal compromise of $50.6-48.6 \%$ that required decompression by total laminectomy. Similar to Kim et al., we believe that posterior approaches are easier, more reliable than anterior approaches, and are adequate for canal decompression and restoration [5].

Kyphotic angulation is another point that a clinician should be aware of and it can progress at the long-term follow-up [42]. It has been reported that angulation is less common in patients who had long segment stabilization with an anterior approach [1]. Dvorak et al. shown that the average degree of preoperative kyphosis, $25.4 \pm 18.4^{\circ}$, improved to $7.5 \pm 15.3^{\circ}$ after anterior approach [24]. In the follow-up, the degree of kyphosis further improved to $10.4 \pm 13$.2. Kaneda et al. used a titanium mesh to correct kyphosis and reported that the plate range was $6^{\circ}$ and $10^{\circ}$ at the last follow-up [24]. Reinhold et al. compared posterior, anterior, and combined systems and observed that the combined system was superior to others when it is followed up with the Cobb angle [6]. In our study, there was no statistical difference between the groups in terms of kyphotic angulation ( $p>0.005)$.

Wesner et al. performed a follow-up analysis of TLBF patients treated with an internal fixation and spongiosaplasty technique for a period of 12-30 months [25]. Their analysis examined canal diameter, kyphotic angulation, and vertebral column height. In that study, the spinal canal reconstructed it self up to $91 \%$. Similar to the above study (25), we found no statistically significant difference between the groups who did or did not have intracanal intervention the end of one year $(p>0.005)$. Although we found no significant differences in terms of both radiologic and clinical improvement at one-year follow-up, we prefer not to retropulse free bone fragments because any unnecessary intervention can increase the amount of injury.

\section{Conclusion}

This retrospective analysis showed no significant difference between the two surgical approaches at one-year follow-up. The reduction of free bone fragments extends the time of surgery and can cause additional complications. Based on the results of this study, we believe that there is no need to reduct 
the free bone fragments inpatients with unstable TLBFs and further studies are necessary to better evaluate our results.

\section{Conflict of interest}

None declared.

\section{Acknowledgement and financial support}

None declared.

\section{Ethics}

The work described in this article has been carried out in accordance with The Code of Ethics of the World Medical Association (Declaration of Helsinki) for experiments involving humans; Uniform Requirements for manuscripts submitted to Biomedical journals.

\section{R E F E R E N C E S}

[1] Lee GJ, Lee JK, Hur H, Jang JW, Kim TS, Kim SH. Comparison of clinical and radiologic results between expandable cages and titanium mesh cages for thoracolumbar burst fracture. J Korean Neurosurg Soc 2014;55(3):142-7.

[2] Deng Z, Zou H, Cai L, Ping A, Wang Y, Ai Q. The retrospective analysis of posterior short segment pedicle instrumentation without fusion for thorocolumbar burst fracture with neurological deficit. Sci World J 2014; 457634.

[3] Wessberg P, Wang Y, Irstam L, Nordwall A. The effect of surgery and remodelling on spinal canal measurements after thoracolumbar burst fractures. Eur Spine J 2001;10 (Suppl. 1):55-63.

[4] Oprel PP, Tuinerbreijer WE, Patka P. Combined anteriorposterior surgery versus posterior surgery for thorocolombar burst fractures: a systematic review of literature. Open Orthop J 2010;4:93-100.

[5] Kim MS, Eun JP, Park JS. Radiological and clinical results of laminectomy and posterior stabilization for severe thoracolumbar burst fracture: surgical technique for one stage operation. J Korean Neurosurg Soc 2011;50(Suppl. 3):224-30.

[6] Reinhold M, Knop C, Beisse R, Audigé L, Kandziora F, Pizanis A, et al. Operative treatment of 733 patients with acute thoracolumbar spinal injuries: comprehensive results from the second, prospective, internet-based multicenter study of the Spine Study Group of the German Association of Trauma Surgery. Eur Spine J 2010;19:1657-76.

[7] Li Y, Walker CL, Zhang YP, Shields CB, Xu XM. Surgical decompression in acute spinal cord injury: a review of clinical evidence, animal model studies, and potential future directions of investigation. Front Biol (Beijing) 2014;9 (Suppl. 2):127-36.

[8] Bradford DS, McBride GG. Surgical management of thoracolumbar spine fractures with incomplete neurologic deficits. Clin Orthop 1987;218:201-16.

[9] Ghanayem AJ, Zdeblick TA. Anterior instrumentation in the management of thoracolumbar burst fractures. Clin Orthop 1997;335:89-100.
[10] Kostuik JP. Anterior fixation for burst fractures of the thoracic and lumbar spine with or without neurological involvement. Spine 1988;13(Suppl. 3):286-93.

[11] McAfee PC, Bohlman HH, Yuan HA. Anterior decompression of traumatic thoracolumbar fractures with incomplete neurological deficit using a retroperitoneal approach. J Bone Joint Surg Am 1985;67(Suppl. 1):89-104.

[12] Yan YB, Qi W, Wu ZX, Qiu TX, Teo EC, Lei W. Finite element study of the mechanical response in spinal cord during the thorocolombar burst fracture. PLoS ONE 2012;7(Suppl. 9): e41397.

[13] Boerger TO, Limb D, Dickson RA. Does 'canal clearance' affect neurological outcome after thoracolumbar burst fractures? J Bone Joint Surg Br 2000;82(Suppl. 5):629-35.

[14] Carlson GD, Gorden CD, Oliff HS, et al. Sustained spinal cord compression: part I: time-dependent effect on long-term pathophysiology. J Bone Joint Surg Am 2003;85A(1):86-94.

[15] Dimar JR, Glassman SD, Raque GH, Zhang YP, Shields CB. The influence of spinal canal narrowing and timing of decompression on neurologic recovery after spinal cord contusion in a rat model. Spine 1999;24(Suppl. 16):1623-33.

[16] Fehlings MG, Perrin RG. The role and timing of early decompression for cervical spinal cord injury: update with a review of recent clinical evidence. Injury 2005;36(Suppl. 2): B13-26.

[17] Kaneda K, Abumi K, Fujiya M. Burst fractures with neurologic deficits of the thoracolumbar-lumbar spine. Results of anterior decompression and stabilization with anterior instrumentation. Spine 1984;9(Suppl. 8):788-95.

[18] Cengiz SL, Kalkan E, Bayir A, Ilik K, Basefer A. Timing of thoracolomber spine stabilization in trauma patients; impact on neurological outcome and clinical course. A real prospective (rct) randomized controlled study. Arch Orthop Trauma Surg 2008;128(Suppl. 9):959-66.

[19] Sayer FT, Kronvall E, Nilsson OG. Methylprednisolone treatment in acute spinal cord injury: the myth challenged through a structured analysis of published literature. Spine J 2006;6:335-43.

[20] Danisa OA, Shaffrey CI, Jane JA, Whitehill R, et al. Surgical approaches for the correction of unstable thoracolumbar burst fractures: a retrospective analysis of treatment outcomes. J Neurosurg 1995;83(Suppl. 6):977-83.

[21] Lu DC, Lau D, Lee JG, Chou D. The transpedicular approach compared with the anterior approach: an analysis of 80 thoracolumbar corpectomies. J Neurosurg Spine 2010;12:583-91.

[22] The National SCI Statistical Center. Spinal Cord Injury, Facts and Figures at a Glance. Birmingham: University of Alabama; 2008.

[23] Dvorak MF, Kwon BK, Fisher CG, Eiserloh 3rd HL, Boyd M, Wing PC. Effectiveness of titanium mesh cylindrical cages in anterior column reconstruction after thoracic and lumbar vertebral body resection. Spine (Phila Pa 1976) 2003;28:902-8.

[24] Kaneda K, Taneichi H, Abumi K, Hashimoto T, Satoh S, Fujiya M. Anterior decompression and stabilization with the Kaneda device for thoracolumbar burst fractures associated with neurological deficits. J Bone Joint Surg Am 1997;79:69-83.

[25] Wesner F, Hutzelmann A, Freund M, Besch L, Riemann U, Egbers HJ, et al. CT morphology of fractured thoracolumbar vertebrae after transpedicular spongiosaplasty and use of internal fixator. ROFO 1997;167(Suppl. 3):234-9.

[26] Nesathurai S. Steroids and spinal cord injury: revisiting the NASCIS 2 and NASCIS 3 trials. J Trauma Inj Infect Crit Care 1998;45(Suppl. 6):1088-93.

[27] Wilcox RK, Boerger TO, Hall RM, Barton DC, Limb D, Dickson RA. Measurement of canal occlusion during the thoracolumbar burst fracture process. J Biomech 2002;35:381-4. 
[28] Kim GW, Jang JW, Hur H, Lee JK, Kim JH, Kim SH. Predictive factors for a kyphosis recurrence following short-segment pedicle screw fixation including fractured vertebral body in unstable thoracolumbar burst fractures. J Korean Neurosurg Soc 2014;56(3):230-6.

[29] Denis F. The three column spine and its significance in the classification of acute thoracolumbar spinal injuries. Spine 1983;8:817-31.

[30] Leferink VJ, Nijboer JM, Zimmerman KW, Veldhuis EF, ten Vergert EM, ten Duis HJ. Burst fractures of the thoracolumbar spine: changes of the spinal canal during operative treatment and follow-up. Eur Spine J 2003;12 (Suppl. 3):255-60.

[31] Daniaux H. Technik und erste Ergebnisse der transpedikulären Spongiosa plastic bei Kompressions brüchenim Lenden wir belsäulenbereich. Acta Chir Austriaca 1982;43:79.

[32] Aebi M, Etter C, Kehl T, Thalgott J. Stabilization of the lower thoracic and lumbar spine with the internal spinal skeletal fixation system. Indications, techniques, and first results of treatment. Spine 1987;12:544-51.

[33] Dick W. Osteosyn these schwerer Verletzungen der Brust und Lenden wir belsäule mit dem Fixateur interne. Langenbecks Arch Chir 1984;364:343-6.

[34] Kaya RA, Aydin Y. Modified transpedicular approach for the surgical treatment of severe thoracolumbar or lumbar burst fractures. Spine J 2004;4(2):208-17.
[35] Ghobrial GM, Jallo J. Thoracolumbar spine trauma: review of the evidence. J Neurosurg Sci 2013;57(2):115-22.

[36] Zhang S, Thakur JD, Khan IS, Menger R, Kukreja S, Ahmed $\mathrm{O}$, et al. Anterior stabilization for unstable traumatic thoracolumbar spine burst fractures. Clin Neurol Neurosurg 2015;130:86-90.

[37] Kang MS, Shin YH, Lee CD, Lee SH. Delayed neurological deficits induced by an epidural hematoma associated with a thoracic osteoporotic compression fracture. Neurol Med Chir (Tokyo) 2012;52(9):633-6.

[38] McCormack T, Karaikovic E, Gaines RW. The load sharing classification of spine fractures. Spine 1994;19(15):1741-4.

[39] Roy-Camille R, Saillant G, Mazel C. Plating of thoracic, thoracolumbar and lumbar injuries with pedicle screw plates. Orthop Clin North Am 1986;17:147-59.

[40] Öner FC, Van Gils AP, Faber JA, Dhert WJ, Verbout AJ. Same complication of common treatment schemens of thoracolumbar spine fractures can be predicted with magnetic resonance imaging: prospective study of 53 patient with 71 fractures. Spine 2002;27:629-36.

[41] Sasso RC, Cotler HB. Posterior instrumentation and fusion for unstable fractures and fracture dislocations of the thoracic and lumbar spine. Spine 1993;18:45-60.

[42] Grossbach AJ, Dahdaleh NS, Abel TJ, Woods GD, Dlouhy BJ, Hitchon PW. Flexion-distraction injuries of the thoracolumbar spine: open fusion versus percutaneous pedicle screw fixation. Neurosurg Focus 2013;35(2):E2. 